\title{
PENGARUH KEMAMPUAN KERJA DAN MOTIVASI KERJA TERHADAP KINERJA PEGAWAI DINAS PENANAMAN MODAL DAN PELAYANAN TERPADU SATU PINTU (DPMPTSP) KOTA PADANG
}

\author{
Tessa Risna Dila, Zusmawati \\ STIE "KBP" Padang \\ Tessarisna5@gmail.com
}

\begin{abstract}
The purpose of this study is to examine the effect of work ability and work motivation partially on employee performance. Research uses quantitative methods and data collection techniques through questionnaires. The sample used is 40 permanent employees in the company. Data analysis used is descriptive analysis method by observing the classical assumption test and multiple linear analysis. The results showed that work ability had no effect on employee performance with t count value $-0,929<t$ table 1.687, and sig value 0.359>0.05. While the variable work motivation had a positive and significant effect on employee performance with a value of $t$ count 3.478> t table 1.687, and the sig value of $0.001<0.05$. The reason given to the company is that the company can improve the work ability of its employees through trainings given to employees who need it and improve work relations between employees.
\end{abstract}

Keywords: Work Ability, Work Motivation, Employee Performance

\section{PENDAHULUAN}

Perubahan zaman sekarang, mendorong manusia ingin mencapai kehidupan yang lebih baik. Pencapaian tersebut ditunjukan melalui kinerja dan keberhasilan yang diberikan dalam bekerja, Sehingga dibutuhkan kemampuan atau kinerja dari pegawai yang maksimal. Kalau tingkat kerja pegawai rendah, maka kemajuan perusahaan pun akan lambat. Sementara itu di lain pihak, perusahaan ikut serta dalam membantu karyawan mencapai kehidupan mereka agar tercukupi kebutuhan mereka sehari-hari. Dengan cara menyeleksi pegawai baru untuk bekerja di instansi, karena ini instansi mengeluarkan uang untuk membayar gaji para pegawai agar bisa mendapatkan pegawai atau (SDM) yang berkualitas, baik dalam sifat maupun kinerja. Menurut (Agustina, 2005 p. 1) "Pada umumnya organisasi bukan hanya menginginkan pegawai yang pekerja keras tetapi juga yang memiliki semngat kerja yang tinggi. "(Theodora, 2015).

Kantor DinasPenanaman Modal Dan Pelayanan Terpadu Satu Pintu ini merupakan instansi penyedia pelayanan jasa dan pemberian izin usaha berikut perdagangan pada masyarakat yang melaksanakan fungsi dan peninjauannya . Berdasarkan hasil pengamatan yang didapat penulis, bahwa pada instansi ini ditemukan masalah yang sering muncul berkaitan dengan indikasi kemampuan 
kerja pegawainya belum sesuai dengan sop kerja , proses surat izin gangguan (IG) yang ditentukan dalam 15 hari kerja pegawainya menyelesaikan melebihi 15 hari . karena semakin banyaknya izin yang masuk mereka lambat dalam meyelesaikan pekerjannya tepat waktu dan hal ini membuat masyarakat mengeluh. Motivasi dorongan kerja yang di yang seharusnya diberikan kepada pegawai pun tidak ada walaupun pegawai melakukan pekerjaan di luar jam kerja mereka. Sedangkan dalam kinerja pegawai sangat rendah hal ini terlihat karena kelalaian surat izin yang di cetak dan terkadang salah dalam penulisan nama dan jam kerja usaha masyarakat.kelalaian ini disebabkan karena, terkadang mereka mendahulukan kepentingan pribadi atau bersantai- santai di dalam jam kerja.

Faktor utama yang menjadikan pegawai bekerja didalam perusahaan/instansi adalah agar kebutuhannya untuk mengaktulisasikan kemampuan dan potensi yang dimilikinya.

Pemberian motivasi kerja yang baik bisa membuat pegawai melakukan pekerjaannya dengan sangat produktif. Dengan produktifnya pekerjaan seorang pegawai maka akan dapat memajukan perusahaan, itu semua dapat tercapai apabila pegawai terpenuhinya kebutuhan pegawai dan sesuai dengan apa yang mereka harapkan seperti imbalan berupa gaji dan bonus atas prestasi yang telah mereka raih. Sumber daya manusia memegang peran yang sangat penting, sumber daya manusia dipandang sebagai faktor pendorong yang utama dalam menentukan keberhasilan suatu perusahaan. Menimbulkan rasa motivasi pegawai harus dilakukan agar menghasilkan kinerja yang baik, motivasi memberikan penggerak untuk pegawai agar mereka melaksanakan pekerjaan sehingga dapat tercapai tujuan suatu organisasi yang efektif serta efisien (Handoko, 1999). (Murti, 2013)

Kenyataan tersebut menjadikan pengembangan sumber daya manusia menjadi hal yang penting dan wajib untuk dilakukan dalam upaya untuk meningkatkan kinerja para pegawai. Upaya pengembangan sumber daya manusia pada dasarnya merupakan langkah nyata yang dilakukan oleh instansi untuk memberikan jaminan bahwa tujuan yang ditetapkan dapat dicapai secara maksimal. Kondisi ini juga berlaku bagi instansi pemerintah yang selalu berupaya untuk memberikan pelayanan yang terbaik kepada masyarakat, salah satunya yaitu Kantor Pelayanan Terpadu. Sesuai Sesuai dengan Undang-undang Nomor 32 Tahun 2004 tentang pemerintah daerah antara lain di tegaskan bahwa tujuan pemberian otonomi daerah adalah untuk memberikan peningkatan pelayanan dan kesejahteraan yang semakin baik kepada masyarakat. Kualitas layanan pemerintah merupakan salah satu indikator keberhasilan otonomi daerah.

Kantor Dinas Penanaman Modal Dan Pelayanan Terpadu Satu Pintu ini merupakan instansi penyedia pelayanan jasa dan pemberian izin usaha berikut perdaganggan pada masyarakat yang melaksanakan fungsi dan peninjauannya. Berdasarkan pengamatan yang dilakukan oleh peneliti kemampuan kerja pegawainya belum sesuai dengan sop kerja ,proses surat izin gangguan (IG) yang ditentukan dalam 15 hari kerja pegawainya menyelesaikan melebihi 15 hari.karena semakin banyaknya izin yang masuk mereka lambat dalam meyelesaikan pekerjannya tepat waktu dan hal ini membuat masyarakat mengeluh. Motivasi dorongan kerja yang seharusnya diberikan kepada pegawai pun tidak ada, walaupun pegawai melakukan pekerjaan di luar jam kerja mereka. 
Sedangkan dalam kinerja pegawai sangat rendah hal ini terlihat karena kelalaian surat izin yang di cetak dan terkadang salah dalam penulisan nama dan jam kerja usaha masyarakat. Kelalaian ini disebabkan karena, terkadang mereka mendahulukan kepentingan pribadi atau bersantai- santai di dalam jam kerja dan kurang teliti dalam menginput surat izin.

Salah satu aspek yang paling sulit dihadapi manajemen pada seluruh organisasi saat ini adalah bagaimana membuat karyawan mereka bekerja secara efisien. Aspek organisasi telah menyebabkan sebagian besar industri menggunakan strategi yang digunakan untuk memotivasi kekuatan kerja mereka. kebanyakan literature dalam studi organisasi.Kemampuan kerja menunjukkan kecakapan seseorang seperti kecerdasan dan keterampilan. Kemampuan berhubungan erat dengan kemampuan fisik dan mental yang dimiliki orang untuk melakaksanakan pekerjaan. (Arini \& Mukzam, 2015)

Pemberian motivasi kerja eksternal dan internal yang makin baik dapat mendorong karyawan bekerja dengan makin produktif. Dengan produktivitas kerja yang tinggi, ongkos karyawan per unit produksi bahkan akan semakin rendah. Selain itu, pemberian kesempatan kepada setiap karyawan untuk berkembang, memenuhi kebutuhan-kebutuhannya berdasarkankemampuan dan kompetensi individu merupakan bagian terpenting dari upaya pemberian pemenuhan kebutuhan bagi karyawan, terutama pada upaya memupuk motivasi kerja karyawan ke arah produktivitas yang lebih tinggi, sebab dengan adanya pemenuhan kebutuhan yang sesuai dengan harapan karyawan, terutama imbalan finansial berupa gaji dan bonus atas prestasi kerja mereka, maka memungkinkan karyawan berkonsentrasi penuh terhadap pekerjannya.

Sumber daya manusia memegang peran yang sangat penting, sumber daya manusia dipandang sebagai faktor pendorong yang utama dalam menentukan keberhasilan suatu perusahaan. Memacu motivasi pegawai harus dilakukan untuk mendorong pencapaian kinerja yang baik. Motivasi merupakan proses pemberian motif (penggerak) bekerja kepada para pegawai sehingga mereka mau bekerja demi tercapainya tujuan perusahaan secara efektif dan efisien. Pemberian motif kerja ini terdapat dalam teori kebutuhan hierarki Maslow yang meliputi kebutuhan fisiologis, kebutuhan keamanan, kebutuhan sosial, kebutuhan penghargaan dan kebutuhan aktualisasi diri (Handoko, 1999). (Murti, 2013)

Pegawai dalam suatu perusahaan dapat dimotivasi dengan memberikan apa yang menjadi kebutuhan dan keinginannya. Namun pemberian motivasi kerja dapat menjadi sulit karena apa yang dianggap penting bagi seseorang belum tentu penting bagi orang lain. Kesuksesan dan kinerja perusahaan bisa dilihat dari kinerja yang telah dicapai oleh karyawannya. Terciptanya sumber daya manusia yang berkualitas tidak lepas dari adanya kemampuan dan motivasi kerja dari orang yang bersangkutan. Dengan kata lain, seseorang yang mempunyai motivasi kerja yang tinggi dan didukung oleh kemampuan bekerja yang baik maka akan tercipta kinerja yang tinggi pula. Motivasi merupakan faktor psikologis yang menunjukkan minat individu terhadap pekerjaan, rasa puas dan ikut bertanggung jawab terhadap aktivitas atau pekerjaan yang dilakukan. Motivasi seseorang biasanya ditunjukkan oleh aktivitas yang terus menerus dan selalu berorientasi pada tujuan. 
Sejalan dengan uraian di atas Dinas Penanaman Modal Dan Pelayanan Terpadu Satu Pintu juga berupaya meningkatkan kinerja organisasi, salah satu upaya peningkatan kinerja organisasi dengan meningkatkan kinerja sumber daya manusia dari karyawannya. Program peningkatan kinerja karyawan Dinas Penanaman Modal Dan Pelayanan Terpadu Satu Pintu Kota Padang antara lain berupa peningkatan kemampuan dan pemberian motivasi karyawan. Peningkatan kemampuan karyawan dilakukan dengan cara memberikan pelatihan kepada karyawannya. Pelatihan dilakukan sebelum penugasan yang disebut pelatihan pratugas untuk menyiapkan pengetahuan, ketrampilan, sikap dan mental sehingga siap melaksanakan tugas. Selain itu pelatihan juga dilaksanakan di pertengahan penugasan yaitu pelatihan penyegaran yang berguna untuk mensosialisasikan kebijakan, prosedur dan peraturan baru.

Secara umum, kinerja karyawan diyakini dipengaruhi oleh kompensasi, motivasi dan komitmen dari karyawan itu sendiri pada akhirnya kinerja tersebut akan berdampak pada kinerja organisasi. Motivasi secara sederhana dapat dirumuskan sebagai kondisi atau tindakan yang mendorong seseorang untuk melakukan sebuah pekerjaan atau kegiatan semaksimal mungkin untuk berbuat dan berproduksi. Seorang yang memiliki motivasi yang rendah mereka cenderung untuk manampilkan perasaan tidak nyaman dan tidak senang terhadap pekerjaannya. Sehingga semakin besar motivasi yang dimiliki oleh individu sebagai karyawan dapat meningkatkan kinerja karyawan itu sendiri.

Pegawai merupakan penggerak operasi organisasi, sehingga jika kinerja pegawai meningkat, maka kinerja organisasi juga akan meningkat. Para pegawai diarahkan untuk meningkatkan kinerjanya agar memiliki sikap dan perilaku yang mencerminkan tanggung jawab, loyalitas, serta kedisiplinan. Untuk mencapai kinerja terbaik organisasi berkepentingan melakukan penilaian terhadap pelaksanaan tugas pekerjaan yang dihasilkan oleh para pegawai sesuai dengan rangkaian sistem yang berlaku dalam organisasi. semakin ketatnya tingkat persaingan bisnis mengakibatkan perusahaan dihadapkan pada tantangan untuk dapat mempertahankan kelangsungan hidup.

\section{Kerangka Pemikiran}

Berdasarkan uraian diatas penulis mencoba untuk membuat kerangka pemikiran dan yang akan menjadi objek penelitian .

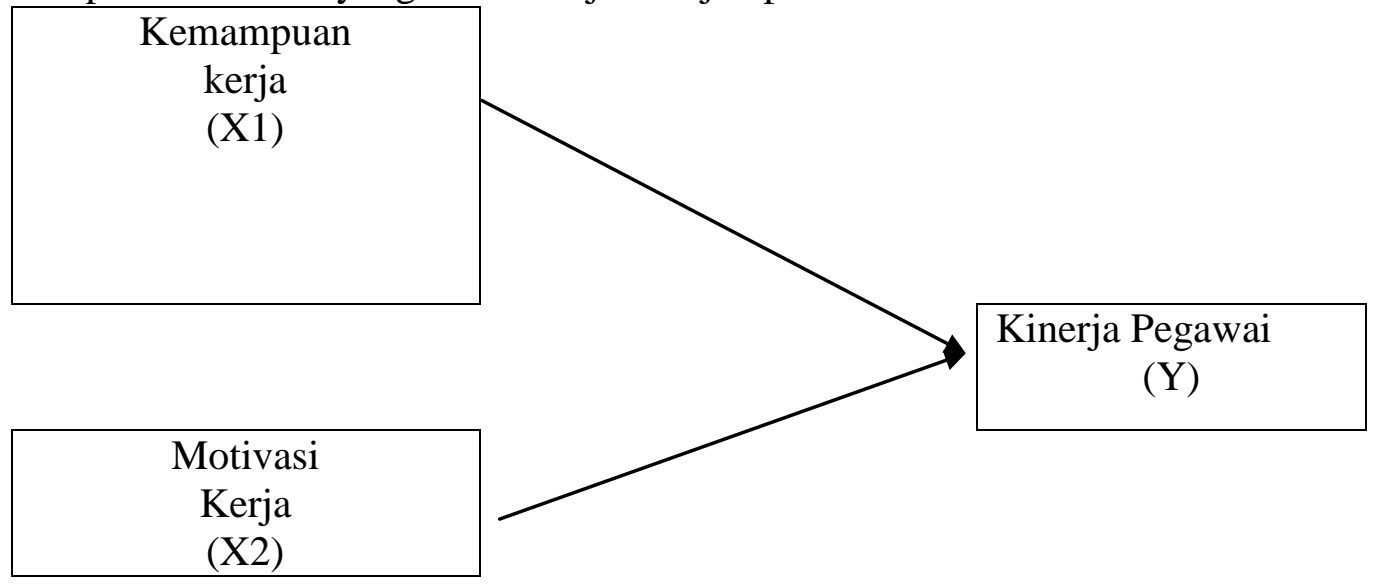


Pengembangan Hipotesis

1. Pengaruh Kemampuan Kerja Terahadap Kinerja Pegawai

Kemampuan adalah bakat yang ada pada seseorang untuk melakukan suatu kegiatan secara fisik atau mental yang ia peroleh sejak lahir, belajar, dan dari pengalaman (Soehardi,2003:24), selain itu kemampuan adalah kapasitas seorang individu untuk melakukan beragam tugas dalam suatu pekerjaan.

Hasil Penelitian ini diperkuat oleh penelitian yang dilakukan oleh penelitian Astuti, Haryono dan Warso (2017) yang berjudul "Analisis Pengaruh Rekruitmen, Kemampuan, Kepribadian, Motivasi, dan Komitmen Terhadap Kinerja Sumber Daya Manusia pada PT. Bina Jasa Sumber Sarana" menyatakan bahwa kemampuan tidak berpengaruh terhadap kinerja pegawai. (Aziz, 2017)

2. Pengaruh Motivasi Kerja Terhadap Kinerja Pegawai

Motivasi kerja adalah rasa yang tumbuh dalam diri seseorang agar bekerja dan mengoptimalkan kinerja untuk mencapai suatu tujuan." (Siagian, 2004: 138).(suwati, 2013). Hasil penelitian ini sesuai dengan hasil penelitian yang dilakukan oleh Murty dan Hudiwinarsih (2012) yang berjudul pengaruh kompensasi, motivasi dan komitmen organisasional terhadap kinerja karyawan bagian akuntansi pada perusahaan manufaktur di surabaya menemukan bahwa motivasi kerja memiliki pengaruh positif terhadap kinerja karyawan. (hidayat, 2017).

\section{METODE PENELITIAN}

\section{Jenis Penelitian}

Jenis penelitian ini adalah penelitian kausal yang menguji hubungan sebab akibat antara dua variabel. Adapun jenis data dari penelitian ini adalah data kuantitatif, yaitu data yang dapat diinput ke dalam skala pengukuran statistik dan disajikan dalam angka-angka (Sugiyono, 2012).(Sugiharta, 2017)

\section{Populasi Dan Sampel}

Populasi penelitian ini adalah seluruh pegawai di Kantor DPMPTSP kota padang berjumlah 40 orang. Seluruh anggota populasi dijadikan sampel, sehingga jumlah sampel dalam penelitian ini yaitu 40 orang. Teknik pengambilan sampel dalam penelitian ini menggunakan total sampling yaitu teknik dimana jumlah sampel sama dengan jumlah populasi. 


\section{HASIL PENELITIAN}

Uji Asumsi Klasik

One-Sample Kolmogorov-Smirnov Test

\begin{tabular}{llr}
\hline & \multicolumn{2}{c}{ Unstandardized Residual } \\
\hline $\mathrm{N}$ & & 40 \\
Normal Parameters ${ }^{\mathrm{a}}$ & Mean & .0000000 \\
& Std. Deviation & 4.81813295 \\
Most Extreme Differences & Absolute & .116 \\
& Positive & .116 \\
& Negative & -.105 \\
Kolmogorov-Smirnov Z & & .732 \\
Asymp. Sig. (2-tailed) & & .658 \\
\hline
\end{tabular}

a. Test distribution is Normal.

Berdasarkan hsil pengolahan data diatas terlihat bahwa nilai Asymp.sig sebesar $0,658>0,05$, maka dapat disimpulkan bahwahasil uji normalitas Kolmogrov-smirnov datatersebut terdistribusi normal.karenanilai signifikan lebih besar dari 0,05 .

\section{UJI MULTIKOLINEARITAS} Coefficients $^{\mathrm{a}}$

\begin{tabular}{llcc}
\hline \multirow{2}{*}{ Model } & & \multicolumn{3}{c}{ Collinearity Statistics } \\
\cline { 3 - 4 } 1 & (Constant) & Tolerance & VIF \\
\cline { 2 - 4 } & Kemampuam Kerja & .516 & 1.939 \\
& Motivasi Kerja & .516 & 1.939 \\
\hline
\end{tabular}

Berdasrkan hasil pengelolahan data diatas pada tabel dapat dilihat bahwa masing- masing variabel independen memilikki nilai tolerance $>0,1$ dan masingmasingvariabel independen VIF $<10$ berdasarkan hasil pengolahan data diatas maka dapat disimpilkan diatas maka dapat disimpulkan bahwa penelitian ini terbebas dari masalah multikolineritas.

\section{Uji Heteroskedastisitas Glejser}

\begin{tabular}{|c|c|c|}
\hline \multicolumn{3}{|c|}{ Model } \\
\hline \multirow[t]{3}{*}{1} & (Constant) & .003 \\
\hline & Kemampuan Kerja & .359 \\
\hline & Motivasi Kerja & .001 \\
\hline
\end{tabular}

Berdasarkan hasil uji heteroskedastisitas diatas dapat diketahui bahwa nilai signifikan variable kemampuan kerja adalah 0,451 dan motivasi kerja sebesar 0,079 yang berarti nilai kedua variabel tersebut $>0,05$. Jadi dapat disimpulkan pada seluruh nilai pada variabel kemampuan kerja dan motivasi kerja bebas gejala heteroskedastisitas. 


\section{Analisa Regresi Liniear Berganda}

Hasil Pengujian Regresi Linear Berganda $(\mathrm{X} 1, \mathrm{X} 2-\mathrm{Y})$

Coefficients $^{\mathrm{a}}$

\begin{tabular}{|c|c|c|c|c|c|c|}
\hline \multirow[b]{2}{*}{ Model } & & \multicolumn{2}{|c|}{$\begin{array}{l}\text { Unstandardized } \\
\text { Coefficients }\end{array}$} & \multirow{2}{*}{$\begin{array}{c}\begin{array}{c}\text { Standardized } \\
\text { Coefficients }\end{array} \\
\text { Beta }\end{array}$} & \multirow[b]{2}{*}{$\mathrm{t}$} & \multirow[b]{2}{*}{ Sig. } \\
\hline & & $B$ & Std. Error & & & \\
\hline \multirow[t]{3}{*}{1} & (Constant) & 22.948 & 7.285 & & 3.150 & .003 \\
\hline & Kemampuan_kerja(X1) & -.185 & .199 & -.177 & -.929 & .359 \\
\hline & Motivasi_Kerja(X2) & .473 & .136 & .663 & 3.478 & .001 \\
\hline
\end{tabular}

Berdasarkan hasil olah data diatas, maka dapat disusun persamaan regresi berganda sebagai berikut :

$\mathrm{Y}=22,948+0,185 \times 1+0,473 \times 2$.

Dari persamaan regresi di atas maka dapat diinterpretasikan beberapa hal antara lain :

1. Nilai konstanta persamaan di atas sebesar 22,948 Angka tersebut menunjukkan tingkat Kinerja Pegawai bila tingkat Kemampuan Kerja dan Motivasi Kerja diabaikan.

2. Variabel Kemampuan Kerja memiliki nilai koefisien regresi sebesar 0,185 . Nilai koefisien negatif menunjukkan hubungan yang negatif antara Kemampuan Kerja terhadap tingkat Kinerja Pegawai. Hal ini berarti bahwa jika terjadi kenaikan variabel Kemampuan Kerja, maka nilai Kinerja Pegawai akan mengalami peningkatan sebesar -0,185 dengan asumsi variabel independen yang lain dianggap konstan.

3. Variabel Motivasi Kerja memiliki nilai koefisien sebesar 0,473. Hal ini juga menunjukkan hubungan positif motivasi kerja terhadap Kinerja Pegawai. Dapat disimpulkan bahwa jika terjadi kenaikan Motivasi Kerja maka nilai Kinerja Pegawai akan mengalami peningkatan sebesar 0,473 dengan asumsi variabel independen yang lain dianggap konstan.

4. Dari kedua nilai antara variabel Kemampuan Kerja dan Motivasi Kerja terdapat perbedaan dimana variabel Motivasi Kerja berpengaruh lebih besar terhadap Kinerja Pegawai dibanding .

\section{Uji T (Parsial)}

\begin{tabular}{lcc}
\hline \multicolumn{1}{c}{ Model } & $\mathrm{T}$ & sig \\
\hline Constant & 3.150 & 0,003 \\
\hline Kemampuan Kerja & 0,929 & 0,359 \\
\hline Motivasi Kerja & 3.478 & 0,001
\end{tabular}

Sumber : Data diolah SPSS

1. Dari tabel diatas terlihat bahwa Kemampuan Kerja memiliki nilai koefisien regresi positif dengan nilai t hitung sebesar 0,929 dengan nilai sig sebesar 0,359. Jika dibandingkan dengan ( $\mathrm{t}$ tabel, sig 0.05, df $(40-3)=$ 37 ). Maka dapat terlihat bahwa dengan nilai t hitung 0,929< t tabel 1,687, dan nilai sig 0,359>0.05, maka dapat disimpulkan bahwa $\mathrm{H0}$ diterima dan H1 ditolak artinya bahwa kemampuan kerja tidak berpengaruh dan tidak signifikan terhadap Kinerja Pegawai. 
2. Dari tabel diatas terlihat bahwa motivasi kerja memiliki nilai koefisien regresi positif dengan nilai t hitung sebesar 3.478 dengan nilai sig sebesar 0,001. Jika dibandingkan dengan ( t tabel, sig 0.05, df $(40-3)=37)$. Maka dapat terlihat bahwa dengan nilai t hitung $3.478>\mathrm{t}$ tabel 1,687, dan nilai sig 0,001 < 0.05, maka dapat disimpulkan bahwa H1 diterima dan H0 ditolak artinya bahwa motivasi kerja berpengaruh dan signifikan terhadap Kinerja Pegawai.

\section{KESIMPULAN}

Berdasarkan hasil pengujian dan pembahasan mengenai pengaruh kemampuan kerja dan motivasi kerja terhadap kinerja pegawai pada Dinas penanaman modal dan pelayanan terpadu satu pintu (DPMPTSP) Kota Padang, maka dapat ditarik kesimpulan, antara lain:

1. Dari tabel diatas terlihat bahwa Kemampuan Kerja memiliki nilai koefisien regresi negatif dengan nilai t hitung sebesar -0,929 dengan nilai sig sebesar 0,359. Jika dibandingkan dengan ( $\mathrm{t}$ tabel, sig 0.05, df (40-3) $=$ 37 ). Maka dapat terlihat bahwa dengan nilai t hitung $-0.929<\mathrm{t}$ tabel 1,687, dan nilai sig 0,359> 0.05, maka dapat disimpulkan bahwa $\mathrm{H} 0$ diterima dan $\mathrm{H} 1$ ditolak artinya bahwa kemampuan kerja tidak berpengaruh dan tidak signifikan terhadap Kinerja Pegawai.

2. Dari tabel diatas terlihat bahwa motivasi kerja memiliki nilai koefisien regresi positif dengan nilai $\mathrm{t}$ hitung sebesar 3.478 dengan nilai sig sebesar 0,001. Jika dibandingkan dengan ( $t$ tabel, sig 0.05, df $(40-3)=37$ ). Maka dapat terlihat bahwa dengan nilai t hitung $3.478>\mathrm{t}$ tabel 1,687 , dan nilai sig 0,001<0.05, maka dapat disimpulkan bahwa H1 diterima dan H0 ditolak artinya bahwa motivasi kerja berpengaruh dan signifikan terhadap Kinerja Pegawai.

3. Variabel kemampuan kerja (X1) dan motivasi kerja (X2) memiliki pengaruh dengan tingkat signifikan masing-masing terhadap variabel kinerja pegawai (Y). Dan motivasi kerja lebih dominan berpengaruh terhadap kinerja pegawai, hal ini dibuktikan dengan koefesien regresi motivasi kerja berbanding lebih besar dengan variabel kemampuan kerja berdasarkan dari penelitian yang dilakukan peneliti pada Dinas Penanaman Modal dan Pelayanan Terpadu Satu Pintu (DPMPTSP) Kota Padang.

\section{UCAPAN DAN TERIMAKASIH}

Dengan selesainya artikel penelitian Bapak Febryandhie Ananda, SE, M.Si selaku Ketua STIE "KBP” Padang yang telah memberikan bimbingan dan fasilitas selama penulis menjadi mahasiswi. Ibu Lidhya Marta, SE, MM selaku Wakil Ketua STIE “KBP” Padang. Ibu Febsri Susanti, SEI, MM selaku Ketua Program Studi Manajemen di STIE "KBP” Padang. Ibu Maria Magdalena, SPd,M.M selaku Dosen Pembimbing Akademik Program Studi Manajemen di STIE "KBP" Padang. Ibu Zusmawati, SE, MM selaku Dosen Pembimbing Skripsi dan artikel yang telah bersedia meluangkan waktu untuk membimbing dalam penulisan penelitian ini. Semua Guru, Dosen, dan Staff yang telah berbagi ilmu dan waktunya sehingga membantu penulis menjadi orang yang memiliki ilmu dan 
dapat menyelesaikan tugas akhir ini. Bapak Reza Alfajri, Amd Sebagai Supervisor pada bidang Pelayanan Perizinan Perekonomian serta karyawan yang telah memberi izin penulis untuk melakukan penelitian dan membantu penulis dalam mengumpulkan data penelitian.

\section{DAFTAR PUSTAKA}

Anggraeni,N. (2011). Pengaruh Kemampuan Dan Motivasi Terhadap Kinerja Pegawai Pada Sekolah Tinggi Seni Indonesia (STSI) Bandung.journal penelitian pendidikan, 12(2), 46-62.

Dona, E. (2016). Pengaruh Perencanaan, Prosedur Dan Pengawasan dan Komitmen Organisasi Dalam Pelaksanaan Anggaran Terhadap Kinerja Pegawai Dinas Pekerjaan Umum Kota Pariaman. Jurnal Riset Manajemen dan Akuntansi (Jurmak), 23-35.

Dona, E. (2018). Analisis Motivasi Kerja Ditinjau Dari Lingkungan Kerja Kasus Karyawan LBPP Lia Payakumbuh. Jurnal KBP.

Hidayat, A. Siagian, H.(2017). pengaruh kemampuan dan motivasi kerja terhadap kinerja karyawan pada cv sinar agung.journal agora,5(3),1-9.

Suddin,A. (2014). Pengaruh kepemimpinan, motivasi, dan lingkungan kerja terhadap kinerja pegawai kecamatan laweyan kota surakarta,jurnal manajemen sumber daya manusia4(1), 1-8.

Ismiati, N., \& Zusmawati, Z. (2020). Pengaruh Konflik Peran Ganda Dan Stres Kerja Terhadap Kinerja Polisi Wanita Di Polresta Padang. https://doi.org/10.31219/osf.io/yfjrb

Koesmono,H, T. (2006). Pengaruh Budaya Organisasi Terhadap Motivasi Dan Kepuasan Kerja Serta Kinerja Karyawan Pada Sub Sektor Industri Pengolahan Kayu Skala Menengah Di Jawa Timur,jurnal manajeme \& kewirausaan,7(5),162-179.

kurniawan,A.(2006). Pengaruh kompetensi, motivasi, komunikasi dan kesejahteraan terhadap kinerja pegawai dinas pendidikan.jurnal akutansi, 7(2),78-86.

Larasati,S.Gilang,A. (2014). Pengaruh Motivasi Kerja terhadap Kinerja Karyawan Wilayah Telkom Jabar Barat Utara ( Witel Bekasi ) Sindi Larasati Divisi Telkom Timur. Wilayah Telkom Jabar Barat Utara atau Witel Bekasi merupakan, jurnal manajemen dan organisasi,5(3), 200-213.

Luthfi, R. I. (2014). pengaruh motivasi terhadap kinerja karyawan ( Studi Pada PT Elsiscom Prima Karya , Kantor Perwakilan Surabaya ),jurnal administrasi bisnis, 13(1), 1-8.

Nardo, R. Evanita, Syahrizal, S. (2018). Pengaruh Kepemimpinan Transformasional, Dan Lingkungan Kerja Non Fisik Terhadap Perilaku Inovatif. JEBI (Jurnal Ekonomi dan Bisnis Islam) 3 (2), 209-215

Nardo, R. Evanita, Syahrizal, S. (2019). The Effect of Transformational Leadership and Non Physical Work Environment on Innovative Behavior with Work Motivation as a Mediation For Employees of Tour And Travel Companies In West Sumatera. 2nd Padang International Conference on Education, Economics, Business and Accounting (PICEEBA-2 2018)

Susriyanti, S. Nardo, R. (2019). Pengaruh Fungsi Komunikasi Dan Kepuasan 
Kerja Karyawan Terhadap Pemberian Pelayanan Nasabah PT. BPR LPN Talawi Sakato. Jurnal Administrasi Sosial dan Humaniora 3 (2), 97-111.

Prawatya, A. (2009). Pengaruh motivasi, kemampuan dan disiplin kerja terhadap kinerja karyawan pada pt pln cabang weleri,jurnal manajemen,6(2) 1-18.

Murti, H. (2013). pengaruh kemampuan kerja dan motivasi kerja terhadap kinerja karyawan PDAM Kota Madiun,jurnal riset manajemen dan akuntasi,1(1), $10-17$.

Ayu, P. Rahmizal, M. (2018). Impact of unbalanced economic growth to dynamic trade specialization. Theoretical \& Applied Economics 25 (3)

Putra, RY. Marlius, D. (2019). Pengaruh Pendidikan, Pengalaman Kerja dan Etos Kerja Terhadap Kinerja Pegawai Di KPN Batur. Academic Conference For Management 2.

Rahmizal, M. (2018). Analysis of Indonesia Marine Fisheries with Economic Growth, Population and Effort Effectiveness. European Journal of Engineering and Formal Sciences 1 (1), 65-70

Rahmizal, M. (2018). Pengaruh Pendapatan, Pendidikan, Kesehatan, Modal Sosial Dan Religiusitas Terhadap Kebahagiaan Individu Di Indonesia. Universitas Gadjah Mada

Rahmizal, M. (2017). Analysis of Indonesia Marine Fisheries with Economic Growth, Population and Effort Effectiveness. European Journal of Engineering and Formal Sciences 1 (1), 17-22

Yudistira, D. S., \& Susanti, F. (2019). Pengaruh Motivasi Kerja Dan Budaya Kerja Terhadap Kinerja Karyawan Dinas Pemberdayaan Masyarakat Dan Desa, Pengendalian Penduduk Dan Keluarga Berencana Kabupaten Pesisir Selatan. https://doi.org/10.31227/osf.io/jk54m

Ridho, M., \& Susanti, F. (2019). Pengaruh Stres Kerja Dan Motivasi Kerja Terhadap Kepuasan Kerja Pada Karyawan Bank Mandiri Syariah Cabang Padang. https://doi.org/10.31227/osf.io/pa2cg

Lubis, A. Y. O., \& Susanti, F. (2019). Pengaruh Gaya Kepemimpinan Dan Kompensasi Terhadap Prestasi Kerja Karyawan (Studi pada PT Japfa Comfeed Indonesia (JCI) Tbk Devisi Fam 1. https://doi.org/10.31227/osf.io/7tbrg

Rachmawati, Y. (2013). Pengaruh Kepemimpinan Kepala Sekolah Terhadap Kinerja Guru, jurnal pendidikan ekonom, 1(1), 19-28.

Roscahyo, A. (2013). Pengaruh Gaya Kepemimpinan Terhadap Kinerja Karyawan Pada Rumah Sakit Siti Khodijah Sidoarjo Agung Roscahyo,jurnal ilmu dan riset manajemen,2(12), 1-16.

Shafiah, S. A. Prasetyo, W. Y. (2004). ( Studi Pada Kantor Pelayanan Terpadu Lumajang ),jurnal administrasi publik,2(2), 312-318.

Sugiharta, B.J.(2017). Pengaruh Kemampuan Kerja Dan Motivasi Kerja Terhadap Kinerja Member Oriflame Di Bali Tahun 2017,jurnal jurusan pendidikan ekonomi,10(2),1-10.

Susanty, A. Baskoro, S. W. (2001). Pada Kinerja Karyawan ( Studi Kasus Pada PT . PLN ( PERSERO ) APD Semarang ), jurnal undip,7(2), 77-84.

Suwati, Y. (2013). Pengaruh Kompensasi Dan Motivasi Kerja Terhadap Kinerja Karyawan Pada PT . Tunas Hijau Samarinda, jurnal ilmu administrasi 
bisnis, 1(1), 41-55.

Theodora, O. (2015). Pengaruh Motivasi Kerja Terhadap Kinerja Karyawan PT . Sejahtera Motor Gemilang ,jurnal AGORA,3(2), 187-195.

Widodo, T. (2010). Pengaruh Lingkungan Kerja, Budaya Organisasi, Kepemimpinan Terhadap Kinerja (Studi pada Pegawai Kecamatan Sidorejo Kota Salatiga), jurnal among makarti,3(5), 14-35.

Kristiani, D.A. (2013). Pengaruh Kemampuan Kerja Dan Motivasi Kerja Terhadap Kinerja Karyawan Pada Karyawan Operator pt. Indonesia power unit Bisnis Pembangkitan Semarang ,Journal Of Social And Politic,2(1),17.

Zusmawati, Z \& Hasdi, D. E. (2020). Pengaruh Karakteristik Pekerjaan Dan Stress Kerja Terhadap Kinerja Karyawan Bidang Tp-Op Dinas Psda Prov Sumbar. https://doi.org/10.31219/osf.io/ev6w4 